\title{
Going for the big one
}

\author{
Blockbuster patents enrich university coffers, but can also affect \\ future patenting and research decisions.
}

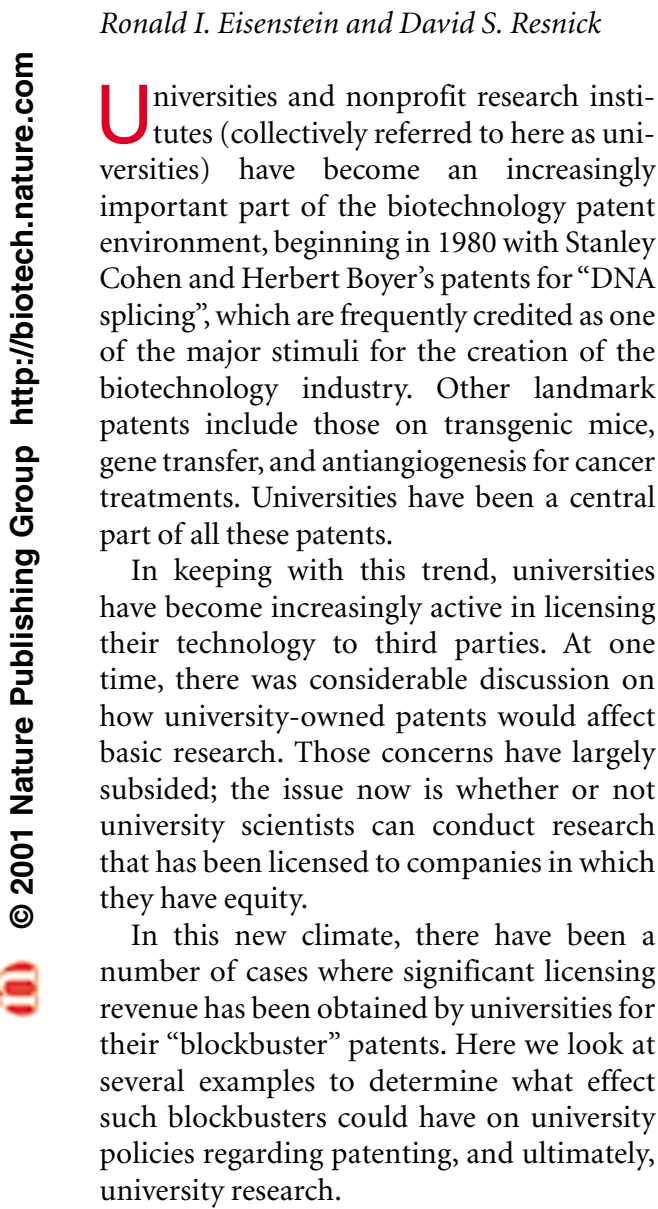

\section{Licensing a blockbuster}

Patents provide a limited monopoly by which the owner of the patent has the right to exclude others from practicing the invention described in the patent's claims. Successful university patents are usually judged not by the scope of the claims or the patent's subject matter (i.e., composition of matter, method of use, method of treatment, or method of synthesis), but rather on how much revenue the university has generated by licensing that patent. Table 1 shows a number of the top revenue-generating patents from the years 1997 to 1998, and Table 2 lists the product, the number of the

Ronald I. Eisenstein and David S. Resnick are partners at Nixon Peabody LLP, 101 Federal Street, Boston, MA 02110-1832 (reisenstein@nixonpeabody.com, dresnick@nixonpeabody.com). patent or patents covering the product, and the type of patent claims.

One patent that must be mentioned in any discussion of university patent licensing is that of Florida State University (FSU) involving the synthesis of Taxol. Now approved by the US Food and Drug Administration (FDA) for the treatment of ovarian, breast, lung, and testicular cancer, Taxol's effectiveness was known at the time of FSU's invention. The problem was that it was obtained from a natural source, and production of the drug was both limited and expensive. The FSU patent claims methods for the preparation of Taxol that overcame those problems. In 2000-2001, the royalty paid to FSU by Bristol-Myers Squibb was about $\$ 67$ million.

\section{Successful university patents are usually judged not by the scope of the claims or the patent's subject matter, but rather on how much revenue the university has generated by licensing that patent.}

Another blockbuster patent is the Cohen-Boyer patent, which actually refers to three patents. One relates to DNA ligation and claims "a method for replicating a biologically functional DNA..." and the other two are product patents: one for proteins produced using recombinant prokaryotic DNA, and the another for proteins from recombinant eukaryotic DNA. The patents were jointly issued to Stanford University and the University of California, San Francisco. Unlike most of the other patents shown in Table 1, Cohen-Boyer was not exclusively licensed to one entity, but rather broadly licensed for a nonexclusive fee. Originally, companies were asked for a $\$ 10,000$ sign-up payment, plus a minimum annual advance of $\$ 10,000$ for a license, plus earned royalties-anywhere from $0.5 \%$ to $3 \%$ of sales, depending on the nature and sales volume of recombinant DNA products. Cohen-Boyer has about 370 current US licensees. The patents have generated over $\$ 200$ million in licensing revenue.

Yale University's patent on Zerit, a synthetic thymidine nucleoside analog, is directed to a method of treatment. Although the patent issued in December 1990, the FDA only approved Zerit in 1994. Zerit has, however, become one of the most widely used ingredients in the drug cocktail used to treat AIDS, and has generated significant revenues.

Another significant university moneymaker is the glaucoma drug Trusopt, which was approved by the FDA in 1994. Last year, Trusopt had over $\$ 127$ million in sales and accounted for $27 \%$ of the US market on glaucoma drugs. The technology was developed at the University of Florida, and the patent for a method of treatment was licensed to Merck.

Finally, a major moneymaker for Michigan State University (and Research Corporation Technology Inc., a company that helps universities patent and license their technology for a percentage of the profits) are patents claiming platinum compounds useful in the treatment of cancer. The first patent issued in 1979, and without patent term extensions, would have expired 17 years later in 1996. Because of appeals in the US Patent and Trademark Office (USPTO), the second patent only issued in 1996, about the same time that the platinum compound Cisplatin was approved for treating ovarian cancer in combination with Taxol. The second patent will not expire until 2013. Accordingly, the university can anticipate obtaining substantial revenues from the latter patent in the coming years.

\section{Common threads}

Although it is difficult to interpret trends from these limited examples, the most striking feature is that most of the patents do not cover "major scientific breakthroughs." For example, in both the Taxol and Trusopt cases, the discovery related to making an existing product more commercially feasible. The market for both drugs was already available, and the importance of the drugs in treatment was known. Taxol's main problem at the time was that extracting and processing the active ingredient, paclitaxel, was very complex, making production of commercial 
Table 1. Top university-owned patents by revenue generation

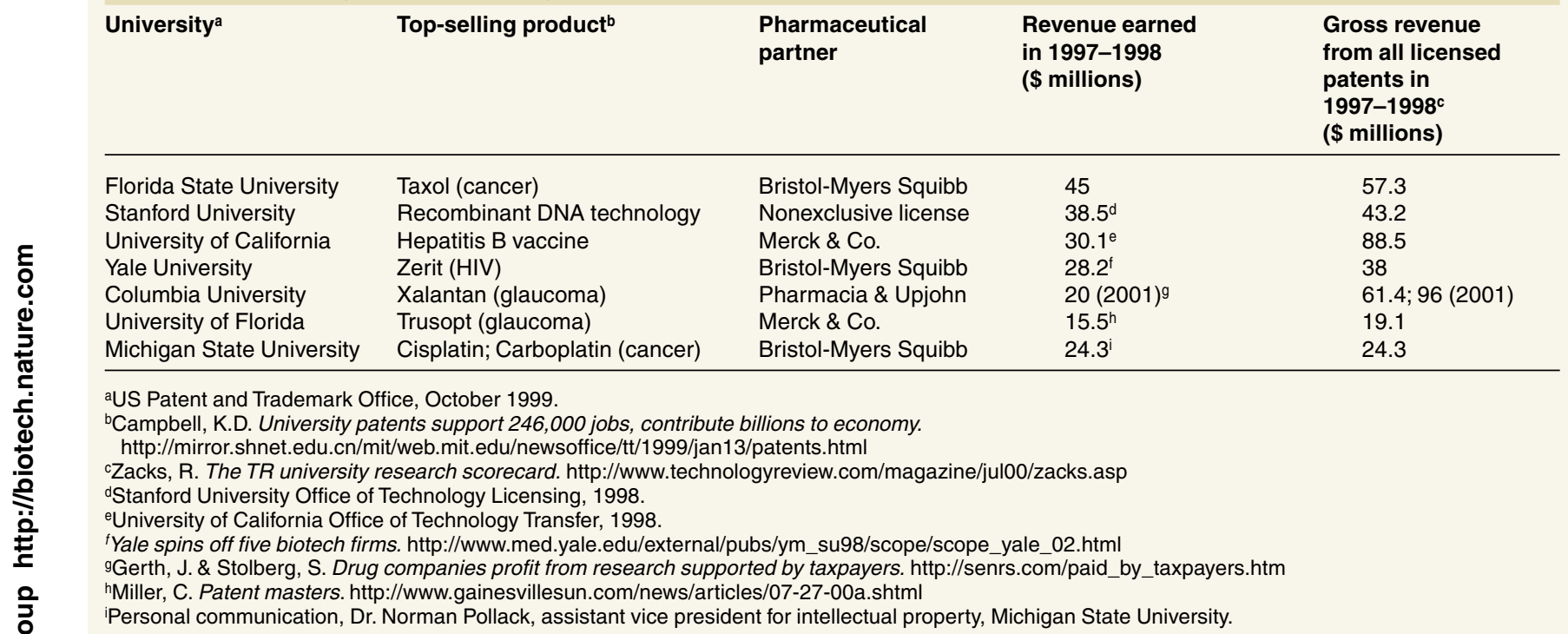

Gross revenue

from all licensed

patents in

1997-1998c

(\$ millions) quantities near impossible. FSU's patented method of synthesis made the production of paclitaxel substantially easier, thereby making Taxol a commercially feasible product. Likewise, the active ingredient in Trusopt was known to be effective in oral form, but the side effects associated with this delivery mechanism were severe. Delivering the active ingredient directly to the eye resulted in a dramatic reduction in side effects.

Cisplatin, by contrast, illustrates the difficulty with developing early-generation compounds. Cisplatin was a cancer treatment looking for a disease. It took 20 years of clinical trials for the drug to be approved, first for testicular cancer, and then later for the treatment of ovarian cancer in combination with Taxol. If not for the fact that patents filed before June 8, 1995 had a patent life span of 17 years from the issue date, and the difficulty encountered in the USPTO in obtaining the second patent, there would have been virtually no patent protection for the university by the time a market was developed, and hence relatively minor royalties.

Most of these blockbusters not surprisingly fall into the area of medical treatment. Furthermore, many of the discoveries could be described as applied, rather than basic

research. Whereas Cohen-Boyer shows that basic research can generate a significant revenue stream, it also suggests that such research needs to be broadly licensed to generate major royalties.

In stark contrast to that approach, most of the other patents have a single pharmaceutical company as a partner. Looking at regulatory delays and patent term, which is now essentially limited to 20 years from the filing date, it

\section{It appears unlikely that any of the breakthrough gene therapy and stem cell patents issued and patent applications filed in the past few years will reach blockbuster status.}

appears unlikely that any of the breakthrough gene therapy and stem cell patents issued and patent applications filed in the past few years will reach blockbuster status. Rather, it will most likely be the second- and third-generation patents that acquire this status.

Table 2. Patent numbers and claims for the top revenue-generating licensed products

Product

Taxol

Cohen-Boyer recombinant

DNA technology

Hepatitis $B$ vaccine

Zerit

Xalantan

Trusopt

Cisplatin

\section{Patent number}

US $5,136,060$

US 4,237,224; US 4,468,464

US $4,740,470$

US $4,415,491$

US $4,978,655$

US $4,599,353$

US $4,619,939$

US 4,140,707; US 5,562,925

\section{Patent claims}

Method of synthesis

Method of use

Composition of matter

Method of treatment

Method of treatment

Method of treatment

Method of use
Of course, there are exceptions to all these observations. Yale's experience with Zerit was relatively quick: the patent was applied for in 1986, and Zerit received regulatory approval in 1994. Zerit was relatively easy for patients to take-one pill, twice a day. The side effects seen with Zerit were less severe than those seen with AZT. Additionally, it takes much longer for patients to develop resistance to Zerit than AZT.

\section{Conclusions}

What does it take to hit the big one? Surprisingly, the common belief that composition-of-matter claims are a critical part of patent protection was not borne out by our analysis. Rather, many of the patents described here are directed to methods. What is important is that the patent provides a significant barrier for entry to the competition. Additionally, there needs to be a market. Finally, there also need to be commercial partners who are willing and able to bring the product to market.

Innovative research is frequently licensed to biotechnology startups. Universities often attempt to obtain equity in such deals in addition to upfront fees, milestone payments, and royalties. The reason for this is that the product, and hence the revenue stream, is so far away. Unfortunately, the biotechnology investment market is highly speculative, and various conflict-of-interest problems can be encountered with this approach.

Thus, it is important that the goal of obtaining significant licensing revenue does not guide research. If it were to have even a small degree of influence, university research could abandon looking for breakthroughs and focus instead on becoming adjuncts to industry. 